\title{
3D Printing in Dental Research
}

\author{
Afnan 0 Al-Zain* \\ Department of Restorative Dentistry, King Abdulaziz University, Saudi Arabia
}

Received: May 30, 2018; Published: June 08, 2018

*Corresponding author: Afnan O Al-Zain, Department of Restorative Dentistry, King Abdulaziz University Faculty of Dentistry (KAUFD), P.O. Box: 80209, Zip Code: 21589, Jeddah, Saudi Arabia

\begin{abstract}
Abbreviations: CAD-CAM: Computer-Aided Design/Computer-Aided Manufacturing; Fab Lab:fabrication laboratory; SLA: stereolithography; PPJ: photopolymer jetting; DLP: digital light processing; EBM: Electron Beam Melting; SLS: Selective Laser Sintering; SLM: Selective Laser Melting; DMLS: Direct Metal Laser Sintering; FDM: Fused Deposition Modeling
\end{abstract}

\section{Introduction}

Over the past decade; advancements in additive manufacturing technologies have been revolutionizing the way we look at things in terms of fabrication, where applications span the spectrum of industrial, medical and dental [1-3]. The incorporation of additive manufacturing/3D printing in dentistry has expanded the possibilities, where 3D printing is being used in oral surgeries, maxillofacial prosthesis, prosthodontics, implantology and dental education $[1,4]$. Further, 3D printing has been also incorporated in dental research through the fabrication of low-volume molds and adapters using different materials with precise dimensions [5].

\section{Types of Manufacturing}

When manufacturing parts/objects; one could use either subtractive or additive manufacturing methods [1,2]. On one hand, subtractive manufacturing is widely used and requires a block of a material to sculpt-out the target part/object by removing material from the original block of material [1,2]. In clinical dentistry, this method has been dominating the industry where it could be used to fabricate crowns and bridges by relying on Computer-Aided Design/Computer-Aided Manufacturing (CAD-CAM) software, which is used as blueprint to guide the machine to sculpt the required part/object $[6,7]$. Conversely in dental research, subtractive manufacturing is used to machine molds that would be used to fabricate samples for testing and evaluation of dental material before its use clinically $[5,8,9]$. when machining molds for dental research, one would typically require a fabrication laboratory (Fab Lab) or a small machine shop to create the required molds. This becomes challenging when one requires mold precision with a small tolerance range and low volume requirement $[10,11]$. However, some simple molds could be fabricated in research laboratories with relative ease; such as, circular molds that can be fabricated using conventional mills that are either vertical or a horizontal [12]. Me tallic and non-metallic materials can be used as raw material to fabricate molds suitable for dental research; such as, stainless steel, brass, Teflon, and Delrin [5,10]. With the introduction of additive manufacturing technologies, an alternative method of fabricating molds is now possible, where it lends itself with may advantages in contrast to conventional subtractive methods. 3D printing is an additive manufacturing method, where an object is manufactured by laying-down the details of the 3D CAD model layer-by-layer using metal or plastic material to form the target part/object [1-3]. The advantages of additive manufacturing over subtractive include efficient use of material with minimal waste, time saving, passive nature of the process, the ability to eliminate manual handling of certain processes, variety of machines that can be used, the wide range and flexibility of the target object geometry, complexity, and variety of materials used [1,2]. As promising as additive manufacturing is and the amount of advancements in recent years; there are some drawbacks that need mentioning. For example, 3D printing equipment and material used for printing are costly, the step-like appearance due to layering of the material, and the difficulty in printing some of the materials used in dentistry such as ceramics $[1,2]$. Nonetheless, additive manufacturing has been a great alternative to subtractive manufacturing to a great extent, where it has replaced its use in some research institutes with access to 3D printing equipment [1-3].

\section{Types of 3D Printing Materials and Techniques}

Overview: There are several techniques and materials used in 3D printing $[1-3,13]$ : examples of the techniques used include but not limited to stereolithography (SLA), photopolymer jetting (PPJ), and digital light processing (DLP); all of which use liquid polymer or resin material that is light curable $[1-3,13]$. Another used technique is powder binder that prints using plaster or cementaceous material that sets and cures using droplets of "colored" water [1-3]. 
A few other methods use sintered powder for 3D printing parts; such as, Electron Beam Melting (EBM) and Selective Laser Sintering (SLS), where the latter can be sued to 3D print polymers and metals [1-3]. For metals, this method is also described as Selective Laser Melting (SLM) or Direct Metal Laser Sintering (DMLS) [1,2]. In addition, Fused Deposition Modeling (FDM) technology uses thermoplastic material that extrudes through a nozzle [1-3]. Also, $3 \mathrm{D}$ printing investment casting may be used to 3D print metals to achieve smooth surface finishes [13-15].

3D Investment Casting: Investment casting is a manufacturing method that is typically used in industry and in dentistry, where it helps achieve precision surface finish [13-15]. In dentistry, investment casting is used to fabricate post and core, crowns and bridges, amongst other things that cater to the needs of the dentist. This method is also called "lost-wax casting" technique where a wax pattern is first created, then dental investment is poured over the pattern, and finally the wax is burned-out and molten metal is poured to take the final shape of the desired part/object $[16,17]$. Fabricating molds using this method may be time consuming if one uses conventional methods to develop the mold pattern tree $[16,17]$. Also, the coefficient of thermal expansion needs to be considered for the wax and molten metal when using this method [1618]. Moreover, each wax pattern is a single-use, where it gets destroyed once it is burnt-out and the cavity is replaced with molten metal that later solidifies to take the final shape of the cavity (void) $[16,17,19]$. In addition, this method is expensive in low-volume due to the tooling cost specifically with smaller parts/objects [18-20].
The process of 3D printing investment casting involves the desired object to be designed and transformed into a 3D model using CAD software, then 3D printed using a polymer material and coated with a ceramic shell, and finally the polymer material is burntout and molten metal is poured into the ceramic shell to take its shape $[14,21]$. Further, 3D printing investment casting can be more efficient than conventional methods due in part to the reduction in the number of processing steps, where it can produce parts/objects with smoother surface finish in contrast to traditional casting methods [13-15]. The superiority of investment casting using 3D printing over traditional methods is because fabricating using 3D printers burns-out the polymer material without residue [20]. This has a great advantage in dental research because small metal molds can be fabricated with smooth surface finish (Figure 1) with relative ease in order to help create samples with smooth surfaces, which is reflected in the end-product that is used by dental researchers [13]. Also, this method has the ability to print patterns directly and fabricate any mold with precision without the need for an elaborate machine shop $[19,22]$. Moreover, minor adjustments are easily performed to the CAD design to account for any molten metal dimensional shrinkage in order to fabricate a mold/object with high accuracy [18]. The iterative process of design changes, rapid fabrication, and evaluating changes using the same digital model can be used to fabricate additional molds with ease. Although 3D printed patterns may cost more than traditional methods; however, in 3D printing; molds are not required, which reduces the time required for fabrication and consequently; reduced the overall cost of low-volume manufacturing by reducing the overall time required to fabricate the objects/molds [19-22].

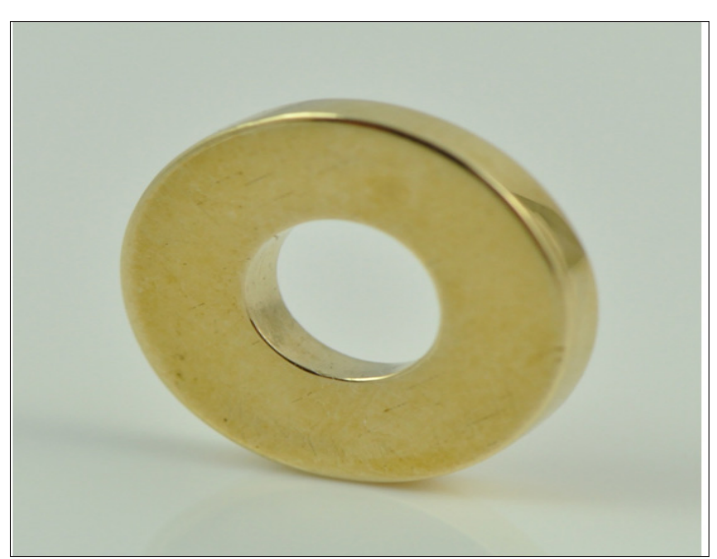

Figure 1: 3D printed investment casting for brass mold. Mold dimensions ( $5 \mathrm{~mm}$ inner diameter $\mathrm{x} 2 \mathrm{~mm}$ thickness).

\section{Conclusion}

3D printing investment casting can be an efficient time-saving method for fabricating accurate molds, which could be used in dental research to test the various properties of developed dental materials prior to using them clinically. As additive manufacturing continues to develop, there would be more material options to consider when 3D printing parts/objects. This will permit further incorporation of additive manufacturing in dentistry and dental research in the coming years minimizing manual work even more. Additive manufacturing can broaden the horizon for dental re- search applications by fabricating various molds, testing fixtures and jig deigns that can be tailored for different experiments. In today's world of ever changing requirements and developments in materials used in dentistry, additive manufacturing allows users to rapidly evaluate their ideas and experiments in ways that allows them to think with their hands.

\section{Acknowledgement}

The technical support and fabrication of prototype molds are acknowledged to DarTec Engineering. 


\section{References}

1. Dawood A, Marti Marti B, Sauret Jackson V, Darwood A (2015) 3D printing in dentistry. Br Dent J 219(11): 521-529.

2. Barazanchi A, Li KC, Al Amleh B, Lyons K, Waddell JN (2017) Additive Technology: Update on Current Materials and Applications in Dentistry. J Prosthodont 26(2): 156-163.

3. Chia HN, Wu BM (2015) Recent advances in 3D printing of biomaterials. J Biol Eng 9: 4.

4. Lynch C (2017) Defining digital dentistry: A survey of recent literature. J Dent 59: 1.

5. Al-Zain AO, Eckert GJ, Lukic H, Megremis SJ, Platt JA (2018) Degree of conversion and cross-link density within a resin-matrix composite. J Biomed Mater Res B Appl Biomater 106(4): 1496-1504.

6. Pfeilschifter M, Preis V, Behr M, Rosentritt M (2018) Edge strength of CAD/CAM materials. J Dent.

7. Mainjot AK, Dupont NM, Oudkerk JC, Dewael TY, Sadoun MJ (2016) From Artisanal to CAD-CAM Blocks: State of the Art of Indirect Composites. J Dent Res 95(5): 487-495.

8. Al-Shehri EZ, Al-Zain AO, Sabrah AH (2017) Effects of air-abrasion pressure on the resin bond strength to zirconia: a combined cyclic loading and thermocycling aging study. Restor Dent Endod 42(3): 206215.

9. Al-Angari SS, Hara AT, Chu TM, Eman Z Al-Shehri (2014) Physicomechanical properties of a zinc-reinforced glass ionomer restorative material. J Oral Sci 56(1): 11-16.

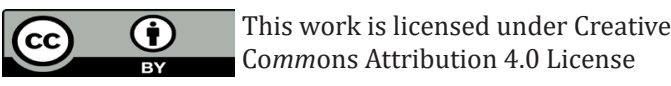

Submission Link: https://biomedres.us/submit-manuscript.php
10. ISO. : No. 4049. Dentistry - Polymer-based filling, restorative and luting materials. 2009.

11. ISO. : No. 13586: Plastics-Determination of fracture toughness - Linear elastic fracture machines (LEFM) approach. 2000.

12. Alsayed H (2017) Effect of interim fixed prosthodontics materials and flowable composite resins on polymerization of polyvinyl siloxane impressions [Indiana University School of Dentistry.

\section{3. www.dartec.com.sa}

\section{4. www.3dprint.com}

15. www.colorfabb.com

16. (2012) Phillips' Science of Dental Materials. Dental waxes, casting invesments, and casting procedures. (12 ${ }^{\text {th }}$ Edition) ELSEVIER.

17. (2011) Craig's Restorative Dental Materials. Replicating materialsimpression and casting. 13th ed: Mosby ELSEVIER.

18. www.stratasys.com

19. www.stratnel.com

20. www.rapidreadytech.com

21. www.aristo-cast.com

22. Kim KB, Kim WC, Kim HY, Kim JH (2013) An evaluation of marginal fit of three-unit fixed dental prostheses fabricated by direct metal laser sintering system. Dent Mater 29(7): e91-96.

$\begin{array}{ll}\text { BIOMEDICAL } & \text { Assets of Publishing with us } \\ \text { RESEARCHES } & \text { - Global archiving of articles } \\ & \text { - Immediate, unrestricted online access } \\ \end{array}$

